\title{
MODERN STATE AND DYNAMICS OF FORMATION OF PHYTOCENOSES IN DIFFERENT ENVIRONMENTS OF THE BAIKAL REGION (Illustrated by central part of western shore of Pre-Baikal)
}

\author{
Tatyana Konovalova ${ }^{1}$, Alexander Sizykh²*, Alexey Shekhovtsov ${ }^{3}$ \\ ${ }^{1}$ Irkutsk State University, 664033, Irkutsk, 126 Ulan-Batorskay str., Russia; \\ ${ }^{2 *}$ Siberian Institute of Plants Physiology and Biochemistry of RAS SB, 664033 Irkutsk, 132 Lermontova str., Russia; \\ ${ }^{3}$ V.B. Sochava Institute of Geography SB RAS, Ulan-Batorskay str., 1, Irkutsk, 664033, Russia; \\ "Corresponding Author Alexander Sizykh, e-mail: alexander.sizykh@gmail.com;
}

Received September 2020; Accepted October 2020; Published November 2020;

DOI: https://doi.org/10.31407/ijees10.419

\begin{abstract}
The revealed structural-dynamic changes in the formation of vegetation in the Baikal region as an integral part of the monitoring of environmental factors variability with time and space allow to make forecasting projects of a probable development vector of vegetation cover under different physical-geographic conditions - zonal-height, interzonal, interheight belts, extrazonal ones at regional-topologic level of environmental organization.
\end{abstract}

Key words: vegetation, structural-dynamics organization of phytocoenoses, ecotopes, Pre-Baikal region 